\title{
Pengembangan Media Pembelajaran Cutaway Transmisi dan Transfer Suzuki SJ-410 dan Torque Converter di Laboratorium Chasis Fakultas Teknik UNY
}

\author{
Muntaha $^{1 *}$, Triwanto ${ }^{1}$ \\ ${ }^{1}$ Universitas Negeri Yogyakarta, 55281 \\ *Coresponding author, email: muntaha@uny.ac.id \\ Submisi: 26 juli 2021; Penerimaan: 30 Agustus 2021
}

\begin{abstract}
ABSTRAK
Pembelajaran merupakan proses pendidikan yang hakekatnya merupakan komunikasi, yaitu metode penyajian gagasan dari seorang pendidik kepada penerima (mahasiswa). Dalam mempermudah pembelajaran diperlukan adanya media dan pengembangan media pembelajaran agar pesan yang sampaikan oleh pendidik dapat diterima dengan dengan baik dan mudah oleh peserta didik.

Tujuan dari penilitian ini adalah membuat dan mengembangkan produk media pembelajaran transmisi dan transfer Suzuki SJ 410 dan Torque Converter untuk pembelajaran di laboratorium Chasis Jurusan Pendidikan Teknik Otomotif. Mengetahui hasil pengembangan media dapat dipergunakan sebagai media pembelajaran.

Penilitian ini merupakan pengembangan media pembelajaran Tranmisi dan transfer Suzuki SJ 410 dan Torque Converter dengan metode Cutway yaitu metode membelah memotong bagian alat untuk mengetahui komponen di dalamnya tanpa mengurangi komponen. Penelitian ini dilaksanakan di Laboratorium Chasis, Jurusan Pendidikan Teknik otomotif UNY. Teknik Pengambilan data menggunakan dokumentasi, wawancara dan observasi. Teknik analisis data yang digunakan teknik analisis deskriptif, sehingga didapatkan rancangan mesin yang aman, berfungsi efektif, dan efisien

Hasil penelitian pengembangan media pembelajaran Tranmisi dan transfer Suzuki SJ 410 dan Torque Converter yang sudah di implementasi dan dapat digunakan untuk pembelajaran di laboratorium chasis sesuai dengan kompetensi yang dibutuhkan dalam pembelajaran. Dengan media pembelajaran Tranmisi dan transfer Suzuki SJ 410 dan Torque Converter yang menarik dan mudah pemahaman sistem kerja alat sehingga proses belajar mengajar berjalan dengan lancar dan dapat memudahkan dosen dalam pembelajaran kepada mahasiswa. Pencapaian hasil belajar mahasiswa sangat baik yaitu sebesar $60 \%$ mendapatkan nilai $A$.
\end{abstract}

Kata Kunci : Media pembelajaran; Tranmisi; Torque Converter

\section{PENDAHULUAN}

Industri otomotif di tanah air sekarang tumbuh dengan cepat. Pengusaha otomotif bersaing dapat menarik hati pemakaidengan produk unggulannya. Kondisi sekarang ini dapat terlihat Ketika kita mengamati berbagai pameran otomif yang biasa dilaksanakan. Masyarakat sangat antusias yang meningkat drastic dengan adanya banyak produk otomotif yang baru dan beragam diluncurkan. Keadaan ini menggambarkan bahwa industry otomotif merupakan peluang meningkatkan ekonomi. Ini berarti industry otomotif ke depan membutuhkan bayak pekerja yang profeisional dan terampil. Peluang kondisi industry yang baik ini perlu dipersiapkan para intansi yang menghasilkan tenaga kerja dimiliki yang 
terampil yang kompenten seperti lulusan SMK dan Perguruan Tinggi yang mempunyai Jurusan Otomotif.

Untuk menyiapkan hasil peserta didik yang handal dan professional diperlukan proses pindidikan/pembelajaran yang baik. Pembelajaran merupakan proses pendidikan yang hakekatnya merupakan komunikasi, yaitu metode penyajian materi/gagasan dari seorang pendidik kepada penerima (mahasiswa). Dalam mempermudah pembelajaran diperlukan adanya media dan pengembangan media pembelajaran agar pesan yang sampaikan oleh pendidik dapat diterima dengan dengan baik dan mudah oleh peserta didik. Kegiatan pembelajaran terkadang terjadi kekeliruan didalam menyampaika materi. Apa yang di sampaikan pendidik dapat terjadi beda persepsi dengan yang diterima oleh perserta didik. Perbedaan ini dapat disebabkan salah satunya akibat adanya keterbatasan media pembelajaran dalam pelaksanaan proses belajar mengajar, sehingga yang di sampaikan pendidik tidak sama dengan yang diterima oleh peserta didik. Proses pembelajaran bisa dikatakan berhasil jika peserta didik dapat memiliki kompetensi sesuai dengan yang diharapkan. Keberhasilan proses pendidikan dengan pembelajarannya dapat di pengaruhi adanya berbagai faktor diantaranya kapasitas pendidik, kemampuan mahasiswa, cara pembelajaranyang dipakai, wahana pendidikan yang tersedia. Wahana prasarana pembelajaranmerupakanperalatan atau benda yang bisa membantu dan mempermudah dalam proses belajar mengajar, sebagai contoh adalah peralatan pendidikan. Media pembelajaran merupakan alat/bahan penghubung yang dapat dipergunakan pendidik dalam menyampaikan materi kepada peserta didik dalam proses pendidikan. Dengan metode cutway pada tranmisi dan Torque Converter peserta didik dapat melihat komponen yang ada di dalam alat tersebut sehingga akan menarik dan mempermudah pendidik dalam memberikan penjelasan kepada mahasiswa.

\section{Latar Belakang}

Di laboratorium Chasis belum adanya media pembelajaran khususnya Tranmisi dan transfer Suzuki SJ 410 dan Torque Converter. Hal tersebut nampak dari minimnya media pembelajaran Tranmisi dan transfer Suzuki SJ 410, bahkan media pembelajaran tersebut belum ada di laboratorium. Kelemahan media pembelajaran yang di memiliki, seperti media belum dapat memperagakan animasi, bentuk media tidak menarik, dan kurang interaktif dalam pembelajaran. Untuk itu dibutuhkan media pembelajaran yang menarik mahasiswa supaya lebih tertarik dan mudah mempelajari materi dengnan pemakaian media-media yang diperlihatkan.

\section{Tujuan Penelitian}

Tujuan dari penelitian adalah membuat dan mengembangkan produk media pembelajaran transmisi dan transfer Suzuki SJ 410 dan Torque Converter dengan metode cutway untuk pembelajaran di laboratorium Chasis Jurusan Pendidikan Teknik Otomotif. Mengetahui hasil pengembangan media dapat dipergunakan sebagai media pembelajaran. Mengetahui implementasi hasil media pembelajaran berpengaruh kepada hasil dan kemampuan mahasiswa di Jurusan Pendidikan Teknik Otomotif.

\section{Manfaat Penelitian}

Dari hasil penelitian media pembelajaran Tranmisi dan transfer Suzuki SJ 410 dan Torque Converter dapat dipakai dalam pembelajaran di 


\begin{abstract}
laboratorium dan meningkatkan kemampuan memahami mahasiswa dalam obyek pendidikan. Memberikan tambahan media pembelajaran khususnya yang berhubungan langsung mahasiswa dalam rangka mengembangkan ilmu pengetahuan pada mata kuliah otomotif di Jurusan otomotif dengan pemakaian media pembelajaran
\end{abstract}

\section{METODE PENELITIAN}

Penelitian ini dilaksanakan di Laboratorium Chasis, Jurusan Pendidikan Teknik otomotif UNY yang dilaksanakan dalam waktu 3 bulan. Penelitian ini yang menjadi objek penelitian adalah Media Pembelajaran Cutaway Transmisi dan Transfer Suzuki SJ 410 dan Torque Converter di Laboratorium Chasis. Metode pengumpulan data dengan dokumentasi, observasi dan wawancara. Dokumen adalah metode pengumpulan data yang diteliti dengan jalan mencatat hal-hal yang penting berkaitan dengan obyek penelitian. Cara ini dapat menghasilakan data yang real, lengkap dan sah sesuai dengan kejadian. Observasi adalah cara mencari data dari tindakan yang terkait dengan penelitian terhadap prosesnya. Dalam sebuah penelitian, observasi digunakan sebagai obyek pemusatan perhatian untuk menghasilkan data. Observasi dapat dikerjakan dengan metode pengamatan dan mencatat yang terjadi dalam suatu dokumen tertentu. Teknik Pengambilan data menggunakan pengumpulan data dengan dokumentasi, observasi dan wawancara. Teknik analisis data yang digunakan teknik analisis deskriptif, hal ini akan mendapatkan hasil rangcangan media yang baik dapat berfungsi dan bernilai efisien.

\section{Prosedur Penelitian}

Penilitian ini merupakan pengembangan media pembelajaran Cutaway Tranmisi dan transfer Suzuki SJ 410 dan Torque Converter sebagai suatu metode untuk dapat mendapatkan produk tertentu, dan menghasilakan nilai efektifi dari sebuah produk. Penilitian ini dilaksanakan di laboratorium Chasis Jurusan Pendidikan Teknik Otomotif Universitas Negeri Yogyakarata.

Didalam pembuatan media pembelajaran diterapkan beberapa tahapan yaitu, perancangan, pembuatan dan pengujian. Teknik pengambilan data dilaksanakan dengan mendokumentasi hasil observasi dan wawancara menghasilkan data yang siap dinalisa sehingga mendapatkan hasil ranncangan media pembeljaran yang aman, berfungsi dan efisiensi. Dari hasil Analisa dibuat rancangan kemudian di diproduksi alat / komponen Tranmisi dan transfer Suzuki SJ 410 dan Torque Converter. Proses selanjutnya adalah uji coba alat yang telah dimodifikasi yang bertujuan utama untuk meningkatkan kualitas hasil praktik mahasiswa sesuai standar industri.

\section{HASIL DAN PEMBAHASAN}

Dari hasil observasi dan pengamatan bahwa media pembelajaran yang berada di laboratorium chasis otomotif JPTO terdiri dari berbagai media pembejaran pada mata kuliah Chasis seperti media pembelajaran sistem kelistrikan mobil dan motor, media pembeljaran sistem kopling, media pembelajaran sistem pengeriman, media pembelajaran sistem pendingin kabin, media pembelajaran sistem penerangan dll. Akan tetapi media pembejaran Tranmisi dan transfer Suzuki SJ 410 belum ada. Untuk itu perlu di buat media pembelajaran agar bisa dengan mudah di pelajari oleh mahasisswa. Media pembelajaran yang ada masih 
seperti pada gambar 1 dimana mesin alat masih berupa mesin berupa block transmisi yang masih utuh, mahasiswa tidak bisa melihat komponen-komponen yang ada di dalamnya.

Karena media pembelajaran tersebut belum ada perlu di buat agar
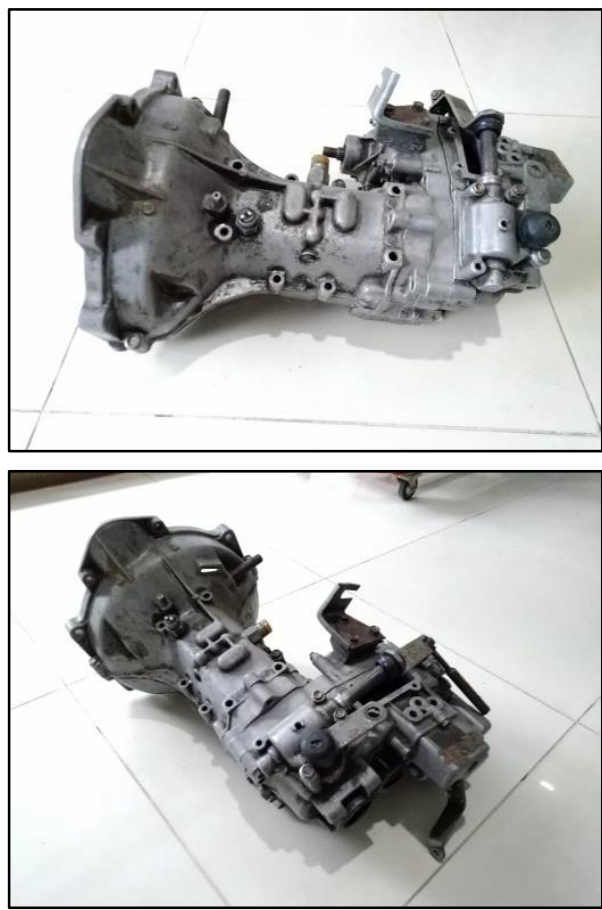

Gambar 1. Block Tranmisi dan transfer Suzuki SJ 410

\section{Media Pembelajaran Transmisi dan Transfer Suzuki SJ 410}

Prosses pendidikan dalam institusi dperlukan adanya suatu proses belajar mengajar /pembelajaran. Pembelajaran merupakan proses pendidikan yang hakekatnya merupakan komunikasi, yaitu metode penyajian materi/gagasan dari seorang pendidik kepada penerima (mahasiswa). Untuk mempermudah penyampaian materi diperlukan adanya suatu media pembelajaran agar materi atau gagasan yang ingin disampaikan dosen bisa di tangkap dengan mudah dan baik oleh mahasiswa sebagai peserta didik. sistem pembelajaran di laboratorium bisa menarik dan mudah dalam penyampaian kepada mahasiswa dan praktikan. Selain itu dosen akan mudah dalam menerangkan kepada mahasiswa.
Kesalahan

diwaktu

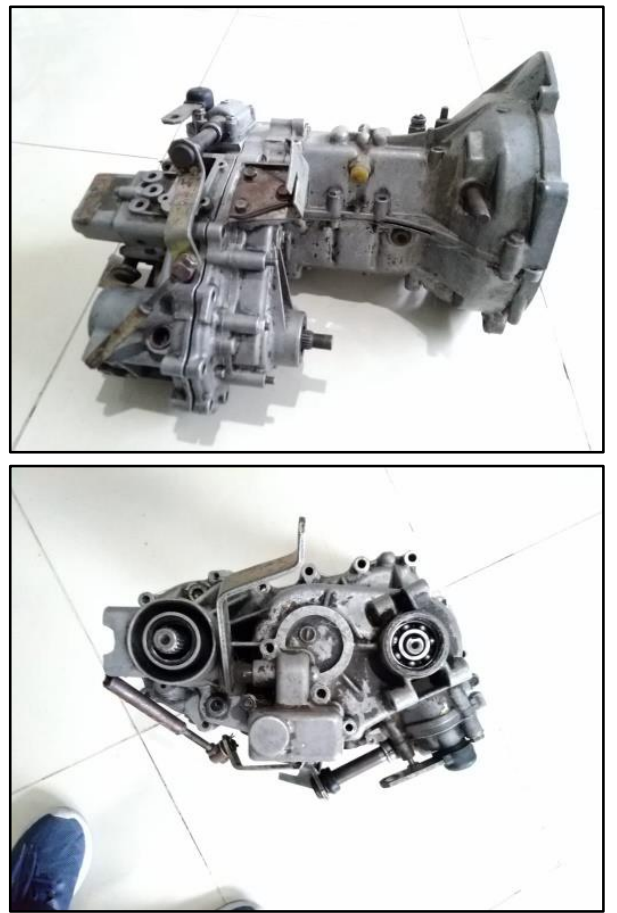

yampaikan ide, gagasan didalam proses pendidikan. Proses pembelajaran atau pendidikan dapat dikatakan berhasil apabila mahasiswa dapat memiliki kompetensi dan keilmuan sesuai dengan yang diharapkan. Keberhasilan proses pendidikan dengan pembelajarannya dapat di pengaruhi adanya berbagai faktor diantaranya kapasitas pendidik, kemampuan mahasiswa, cara pembelajaranyang dipakai, wahana pendidikan yang tersedia. Wahana prasarana

pembelajaranmerupakanperalatan atau benda yang bisa membantu dan mempermudah dalam proses belajar 
mengajar, sebagai contoh adalah peralatan pendidikan. Media pembelajaran merupakan alat/bahan penghubung yang dapat dipergunakan pendidik dalam menyampaikan materi kepada peserta didik dalam proses pendidikan. Median pembelajaran akan mempermudah dalam proses pembelajaran dikarenan mahasiswa akan lebih tertari dan mudah dalam menangkap konsep kerja dari suatu alat yang sedang dipelajari.

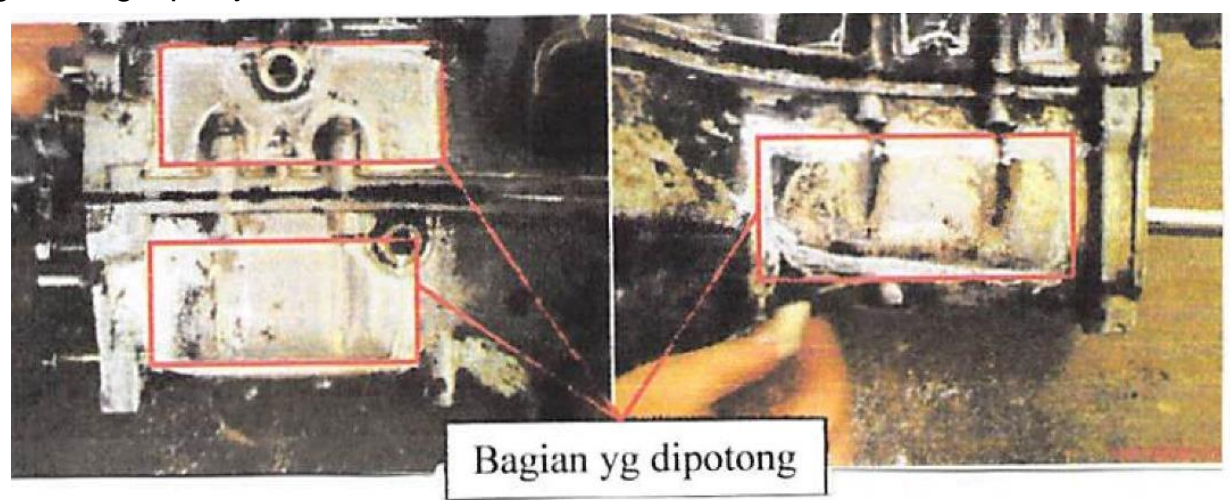

Gambar 2. Penandakan Cutaway block Tranmisi dan transfer Suzuki SJ 410
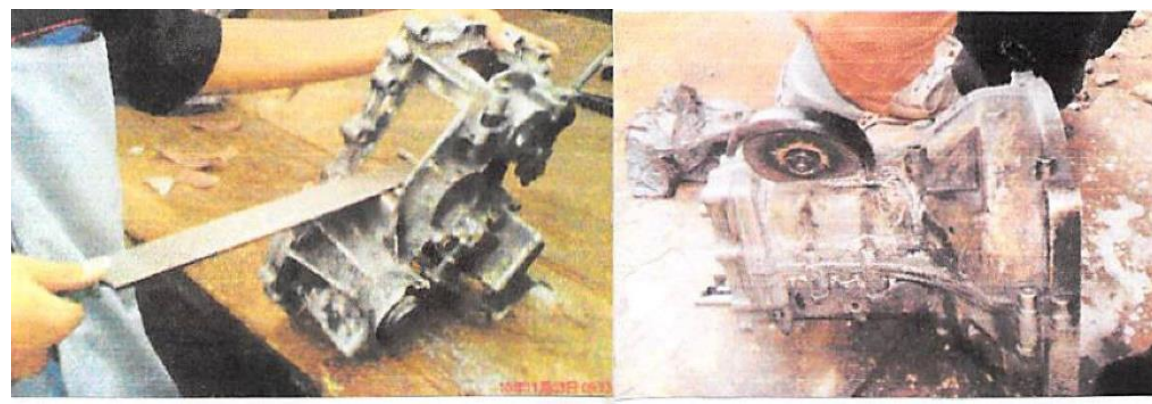

Gambar 3. Pembersihan dan penghalusan dari bekas pemotongan block tranmisi dan Transfer Suzuki SJ 410

Dalam membuat media pembelajaran Cutaway Suzuki SJ 410 dibuat dengan melalui beberapa tahapan antara lain observasi peralatan, perancangan pemotongan, melakukan pemotongan peralatan, merangkai dan menguji hasil rakitan. Proses perencanaan yang dilakukan adalah merancang dudukan transmisi dan transfer yang akan digunakan, merancang dengan menandai bagianbagian pada bagian transmisi dan
Media cutway adalah metode pembelajaran dengan cara membelah atau memotong peralata atau mesin yang sebenarnya tanpa mengurangi komponen yang agar dapat mudah mengamati sistem kerja suatu peralatan mesin. Dengan peralatan di buka seperti itu mahasiswa akan dengan . dan tentunya hal ini juga akan menarik mahasiswa untuk belajar. 
Alat yang digunakan untuk memotong adalah dengan cara di bor bagia rumah mesin yang sudah di tandai. setelah pemotongan selesai di haluskan menggunakan mesin gerinda poles dan di kikir (gambar 3). Media pembejaran yang telah selesai dibuat diuji dengan melakkukan uji fungsional bagian-bagian media dan uji fungsional sebagai media pembelajaran untuk mengetahui fungsi media tersebut.
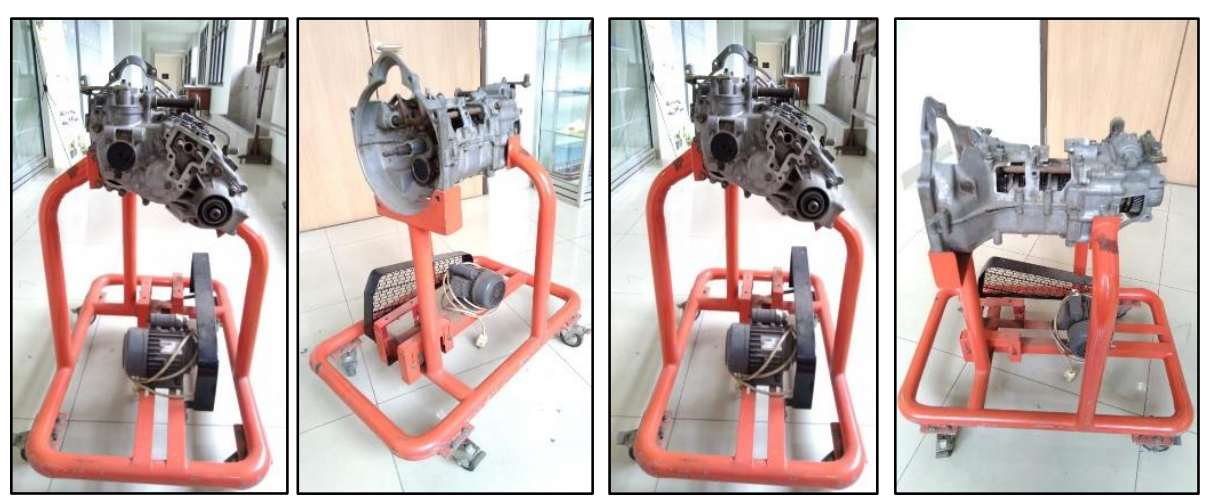

Gambar 4. Media Pembelajaran block tranmisi dan Transfer Suzuki SJ 410
Pada gambar 4 menunjukan adanya motor yang untuk pengujian tranmisi memerlukan putaran pada roda gigi transmisi, dengan memasang sebuah motor listrik yangdi hubungkan dalam sistem transmisi. Dengan menghidupkan motor system kerja transmisi dan transfer tenaga dapat langsung di lihat. Sehingga dengan adanya kelengkapan media pembelajaran diatas mahasiswa akan mudah memahami dan mempelajari sistem tranmisi dan tsansfer pada Suzuki SJ 410.

\section{Media Pembelajaran Cutaway Torque Converter \\ Torque Converter yang bisa di} sebut dengan kopling otomatis. Torque Converter tidak bisa dibongkar pasang jadi kalau ingin melihat atau mengetahui komponen di dalamnya dan cara kerjanya harus di potong atau di belah . Karena bahannya yang tebal untuk
Pada gambar 4 menunjukan adaya rangka dudukan mesin/alat untuk mempermudah mobile dari block mesin perlu di buatkan rangka penopang yang di beri roda sehingga media pembelajaran akan mudah di bawa kemana untuk praktiukum di laboratorium. Rangka di buat dari besi pipa berdiameter 1,5 " yang berbentuk rangka berbentuk persegi ukuran $60 \mathrm{~cm}$ $x 120 \mathrm{~cm}$ tinggi $70 \mathrm{~cm}$ memotong tidak cukup dengan hanya menggunakan gergaji akan tetapi harus menggunakan mesin gerinda potong dan kikir untuk menghaluskan bekas dari potongan. Adapun hasil media ini diharapkan mahasiswa mampu mengetahu cara kerja dari Torque Converter

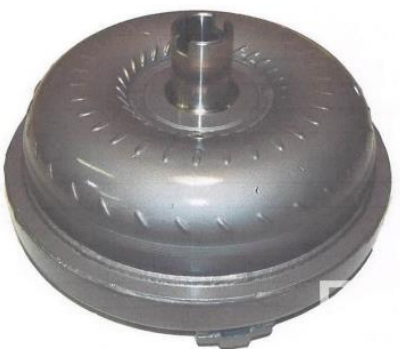

Gambar 5. Torque Converter sebelum di belah

Dari hasil pembelahan Torque Converter mahasiswa dengan mudah dapat mengamati dan mempelajari komponen-komponen di dalamnya. 
Mahasiswa akan lebih mudah menganalisa sistem kerja dari kopling otomatis mobil.

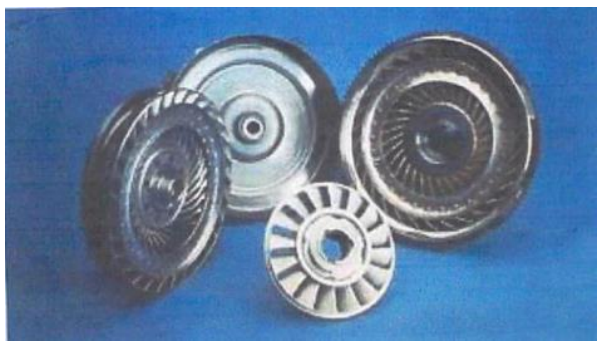

Gambar 6. Bagian-bagian Torque Converter setelah di belah
Tabel 1 menunjukan hasil perolehan nilai praktikum bahwa mahasiswa mendapatkan nilai $\mathrm{A}$ dan Asebayak $60 \%$. Hasil ini menunjukan keberhasilan mahasiswa dalam proses pembelajaran praktik transmisi, transfer Suzuki SJ 410 berjalan dengan baik karena mahasiswa mudah mengamati dan menganalisa system kerja transmisi, transfer dan kopling ini adalah bukti keberhasilan pelaksanaan pembelajaran.

Tabel 1. Penyebaran Penilaian submatakuliah transmisi, transfer Suzuki SJ 410 Mahasiswa.

\begin{tabular}{|c|c|c|c|c|c|c|}
\hline \multirow{2}{*}{ Nilai } & \multicolumn{4}{|c|}{ Kelas } & \multirow{2}{*}{ Jumlah } & \multirow{2}{*}{ Persentase } \\
\hline & $\mathrm{A} 1$ & A2 & B1 & B2 & & \\
\hline$A$ & 9 & 3 & 2 & 4 & 18 & $25 \%$ \\
\hline A- & 5 & 10 & 8 & 5 & 28 & $39 \%$ \\
\hline $\mathrm{B}+$ & 5 & 4 & 6 & 6 & 21 & $29 \%$ \\
\hline B & 1 & 2 & 0 & 0 & 3 & $4 \%$ \\
\hline B- & 0 & 0 & 2 & 0 & 2 & $3 \%$ \\
\hline $\mathrm{C}+$ & 0 & 0 & 0 & 0 & 0 & $0 \%$ \\
\hline C & 0 & 0 & 0 & 0 & 0 & $0 \%$ \\
\hline Jumlah & 20 & 19 & 18 & 15 & 72 & $100 \%$ \\
\hline
\end{tabular}

\section{KESIMPULAN}

Dari hasil penelitian media pembelajaran Tranmisi dan transfer Suzuki SJ 410 dan Torque Converter yang sudah di implementasi dapat disimpulkan :

1. Media pembelajaran Tranmisi dan transfer Suzuki SJ $410 \mathrm{~h}$ dan Torque Converter hasil inovasi dapat digunakan untuk pembelajaran di laboratorium chasis sesuai dengan kompetensi yang dibutuhkan pembelajaran.

2. Dengan adanya media pembelajaran Tranmisi dan transfer Suzuki SJ 410 dan Torque Converter memudahkan pemahaman sistem kerja alat hal ini bisa dilihat dari capaian nilai yang diperoleh mahasiswa $60 \%$ mendapat jilai $A$, dan dapat memudahkan dosen dalam pembelajaran kepada mahasiswa.

\section{DAFTAR PUSTAKA}

Daryanto, 2008, "Pengetahuan Komponen Mobil', Skripta: media Creator .

F. Noviyanto, 2008, “Membangun Sistem Pembelajaran Pengenalan Bentuk untuk Anak Berbasis Multimedia dan Game Interaktif," J. Inform., vol. 2, no. 1, pp. 158-167.

Hadi Prayino, 2018 , "Pemeliharaan Sistem Transmisi Otomatis" , Kanisius,

Modul Praktikum Chasis Otomotif, Jurusan Pendidikan Teknik Otomotif, FT, Universitas negeri Yogyakarta

Pribadi, A Benny, 2009, "Model Desain Sistem Pembelajaran" Jakarta: PT. Dian Rakyat.

Sugiyono. 2011, "Metode Penelitian Kuantitatif Kualitatif dan R\&D", Bandung: Alfabeta.. 
Sukiman, 2012, "Pengembangan Media Pembelajaran," Yogyakarta : PT Pustaka Insan Madani,

Sukoco, Arifin Zainal , 2008, "Teknologi Motor Diesel', Alfabeta.

Wagiran, (2013), Metodelogi Penelitian Pendidikan (Teori dan
Implementasi), Yogyakarta

Deepublish

Wakid Muhkamad, 2011, "Sistem Transmisi Kendaraan Ringan", Skripta media Creator, 